\title{
https://doi.org/10.30853/manuscript.2019.11.54
}

\section{Сюй Цзянь}

\section{СПЕЦИФИКА МУЗЫКАЛЬНОЙ СТИЛИСТИКИ СЫЧУАНЬСКОЙ ОПЕРЫ}

В статье рассмотрена уникальная разновидность китайской традиционной драмы - опера провинции Сычуань, или Сычуаньская опера. Она существенно отличается от известной во всем мире Пекинской оперы и других локальных видов этого искусства. Сычуаньская опера обладает своей эстетикой, техникой и оперной школой, но главное ее достояние - неповторимый музыкальный стиль, который заключается в сочетании оригинального пения в высоком регистре (гаоцян) под аккомпанемент ударных инструментов (логуцзинь) с вокально-хоровым комментированием (банцян). Автор анализирует особенности вокальной стилистики Сычуаньской оперы, детально описывает ударные инструменты, представляет типы хорового комментирования, используемые в опере.

Адрес статьи: www.gramota.net/materials/9/2019/11/54.html

\section{Источник}

\section{Манускрипт}

Тамбов: Грамота, 2019. Том 12. Выпуск 11. С. 288-292. ISSN 2618-9690.

Адрес журнала: www.gramota.net/editions/9.html

Содержание данного номера журнала: www.gramota.net/materials/9/2019/11/

\section{() Издательство "Грамота"}

Информация о возможности публикации статей в журнале размещена на Интернет сайте издательства: www.gramota.net Вопросы, связанные с публикациями научных материалов, редакция просит направлять на адрес: hist@gramota.net 


\title{
FRANZ SCHUBERT'S PIANO VARIATIONS THROUGH THE LENSES OF THE GENRE DEVELOPMENT
}

\author{
Maksimov Evgenii Ivanovich, Doctor in Art Criticism, Associate Professor \\ Moscow P. I. Tchaikovsky Conservatory \\ evgeny.69@list.ru
}

\begin{abstract}
The article is devoted to studying Franz Schubert's piano variations, a poorly investigated sphere of the composer's creative work. These compositions are considered in the context of the genre development and through the lenses of the development of Schubert's conception of the variational cycle. Analysing these musical pieces, the researcher traces relation with Beethoven's tradition of variational composition. The comparative analysis method is applied to compare variational compositions of the two composers who were almost contemporaries. Special attention is paid to dramaturgic peculiarities of Schubert's variations.
\end{abstract}

Key words and phrases: F. Schubert; variations; variational cycle; theme; development.

В статье рассмотрена уникальная разновидность китайской традиционной драмьл - опера провинции Сычуань, или Сычуаньская опера. Она существенно отличается от известной во всем мире Пекинской оперы и других локальных видов этого искусства. Сычуаньская опера обладает своей эстетикой, техникой и оперной школой, но главное ее достояние - неповторимый музыкальный стиль, который заключается в сочетании оригинального пения в высоком регистре (гаоиян) под аккомпанемент ударных инструментов (логуизинь) с вокально-хоровым комментированием (баниян). Автор анализирует особенности вокальной стилистики Сычуаньской оперы, детально описывает ударные инструменты, представляет типы хорового комментирования, используемые в опере.

Ключевые слова и фразы: китайская традиционная драма; региональная специфика; Сычуаньская опера; высокие напевы гаоцян; вокально-хоровое комментирование; аккомпанемент ударных инструментов логуцзинь.

\section{Сюй Цзянь}

Российский государственный педагогический университет имени А. И. Герцена, г. Санкт-Петербург 251104247@qq.com

\section{СПЕЦИФИКА МУЗЫКАЛЬНОЙ СТИЛИСТИКИ СЫЧУАНЬСКОЙ ОПЕРЫ}

Китайская традиционная драма известна во всем мире своей уникальной самобытностью, в которой объединены разные виды искусств и дух военного дела. В эпоху глобальных взаимодействий и стремительно устанавливающихся связей этот вид национальной культуры за пределами Китая получил наименование «китайской оперы», которая «сложилась вне европейских влияний и представляет собой самобытное искусство с уникальной эстетикой и выразительной системой. Самая известная разновидность китайской традиционной драмы - Пекинская опера, которая сложилась в XVIII веке. Название “опера” было ей дано европейцами, не сумевшими обозначить её иначе» [8, с. 3]. Этот вид традиционного китайского театра с энтузиазмом описывали как китайские специалисты, так и российские музыковеды $[1 ; 3-5 ; 8]$.

Однако наряду с Пекинской оперой существуют и другие разновидности традиционного театрального искусства Китая. Территория Китая населена множеством народностей, и закономерно, что китайские провинции сформировали самобытную культурную специфику, проявляющуюся во всей полноте в народных зрелищных искусствах. Театральное наследие провинций запечатлено в региональных разновидностях «китайской оперы», о которых упоминают отдельные исследователи [6-8].

В середине ХХ столетия в Китае были известны 367 видов региональных опер. К концу столетия около 100 региональных видов исчезли, а многие из оставшихся находятся на грани исчезновения. Во второй половине прошедшего столетия в Китае состоялись две крупномасштабные акции спасения национального оперного искусства. В их рамках были записаны на видеоносители тысячи традиционных опер, затем начались систематизация и анализ общего состояния оперного наследия в Китае. В множестве локальных разновидностей были выделены стилеобразующие виды [10]. От них в истории развития традиционной драмы произошли ответвления, которые затем сплетались и образовывали причудливые стилевые миксты или же, смешиваясь с народной традицией местности, порождали порой неузнаваемые варианты этого вида искусства.

В настоящей статье рассматривается Сычуаньская опера, прославившаяся в Китае и за его пределами своей уникальной самобытностью. Актуальность исследования музыкальной стилистики Сычуаньской оперы заключается в том, что древнейший вид театрального искусства - китайская традиционная драма - без привлечения сведений о ее разновидностях до сих пор остается изученной не в полной мере: представление о китайской драме не сводится к описанию Пекинской оперы. Сычуаньская опера обладает своей эстетикой, техникой и оперной школой, она прекрасно отражает красоту китайской театральной культуры, но на сегодняшний день о ней содержится лишь справочная информация, сопровождающая записи этой оперы на CD- и DVD-носителях. 
Цель статьи - представить аналитическое описание особенностей музыкального стиля Сычуаньской оперы как локальной разновидности китайской драмы. Научная новизна состоит в расширении искусствоведческих знаний в отношении музыкальных характеристик китайской традиционной драмы.

История возникновения оперной школы Сычуань уходит своими корнями в далекое прошлое, когда театр был основной духовной пищей для жителей китайских провинций. Показывая мирскую сторону бытия, актеры местного театра исполняли роли, отражающие жизнь разных социальных слоев: от императоров и министров до простых людей - отца и сына, невесток и тетушек. Актеры должны уметь легко управлять разными специфическими манерами пения, которыми так богата китайская певческая традиция [2; 9]. Исполнители облачены в парадные халаты, расшитые драконами, флеровые шапочки, сапоги, при этом не только характерный фасон, но и цветовое решение костюмов несет в себе определенную смысловую нагрузку: так, белый цвет символизирует вероломство, черный - отвагу, красный - честность и справедливость, жалобы на превратности судьбы; музыкальное оформление, основанное на мелодичных переливах струнных и духовых, гонгов и барабанов, также влияет на внутреннее духовное содержание китайских оперных произведений.

Уникальное сочетание черт, присущих китайской оперной традиции в целом и собственной индивидуальности Сычуаньской оперы, максимально обогатило содержание сычуаньского оперного искусства и сделало его форму невероятно многообразной.

В вокальной стилистике оперы объединились специфические способы национального пения, в Китае их называют напевами. Овладение стилистикой и техникой напевов является основой обучения будущего оперного артиста, которую он проходит под руководством мастера традиционного пения.

Напевы являются душой китайской оперной музыки. Напевы в Сычуаньской опере представлены пятью большими видами: «гаоияян, «хуциинь», «куньиян», «танси», «дэнси». Каждый является уникальным, обладает собственным диапазоном, способом звукоизвлечения, динамикой, эстетической окрашенностью. Вместе они сыграли важнейшую роль в становлении сычуаньского оперного искусства. В ранний период его развития пять видов пения существовали и исполнялись отдельно. Лишь после Синьхайской революции (1911 года) постепенно эти виды начали объединяться в единое художественное целое в пространстве одного спектакля. Из-за разницы в языке в разных местностях провинции Сычуань напевы сохранили свою специфику и особую характеристичность. Артист должен уметь не только петь, но и говорить на разных диалектах провинции Сычуань, разумеется, не в их природном виде, а в отшлифованном традицией и школой оперного мастерства. Представим характеристику некоторых певческих стилей, используемых в сычуаньском оперном искусстве.

Гаоцян. Это самый репрезентативный стиль в Сычуаньской опере. В основе «гаоцян» лежит мощное чувственное пение в высоком регистре. В звуковом отношении у песен стиля «гаоцян» самый высокий регистр преимущественно вторая октава и выше; во время исполнения «арии» за кулисами или на сцене подпевают фоновые артисты. Своими весьма значительными вокальными репликами актеры комментируют происходящее на сцене или акцентируют чувства и настроения действующих лиц, вступая в тонкие отношения с солирующей партией.

Высокие напевы - это не только стиль, но и наиболее древний пласт мелодий, которые исполнялись под аккомпанемент гонгов, барабанов и других ударных инструментов. Он отличается театральностью, эффектностью, в нем особо акцентирована драматургия, поскольку пение сочетается с активным комментированием. Так как для этих напевов характерен высокий регистр звучания, они носят общее название «гаоцян» - «высокие напевы», или в системе русского языка точнее будет выражение «стиль пения в высоком вокальном регистре». Из-за того что исполнение «гаоцян» требовало развитого голосового диапазона в высоком регистре, большую популярность «гаоцян» получил в провинциях Аньхой, Чжэцзян, Наньцзин, Хунань, Хубэй, Гуандун, Фуцзянь, в народном творчестве которых культивировалась пронзительнотрагическая манера пения в высоком голосовом регистре.

Гаоцян можно сегодня услышать не только в Сычуань, но и во многих других видах китайской оперы Хунаньской драме, Аньхойской опере, Цзянсийской музыкальной драме. Но в Сычуаньской опере этот стиль имеет самую давнюю историю. В период династий Мин и Цин по различным каналам (переселение людей, торговля, профессиональные контакты) гаоцян проник в Сычуань. Соединение гаоцян с сычуаньским диалектом позволило ему впитать в себя сычуаньские народные мелодии и прочно закрепиться в стилистике Сычуаньской оперы. А в смешении с сычуаньским крестьянским диалектом «дэнси» в сопровождении гонгов и барабанов «гаоцян» получил глубокий отпечаток «сычуанизации» - специфического местного колорита.

Стилистику гаоцян в Сычуаньской опере поддерживают и украшают особые музыкально-драматургические компоненты - хоровое подпевание банцян и аккомпанемент ударных логуцзинь.

Банцян - искусство подпевания или вокально-хорового комментирования - существовало еще в древности, в частности в сычуаньских трудовых песнях. Формы и способы банцян в высоких напевах разнообразны. В зависимости от сценической ситуации банцян предваряет сольное выступление или завершает его; может полифонически сопровождать процесс пения солиста; может, подобно эффекту эха, повторять прозвучавшую фразу, а может быть самостоятельным и не зависеть от пения солиста. Хор-«комментатор» порицает, критикует, сопереживает действующим лицам, например, как в пьесе «Лю Иньцзи - проводы». Если главные действующие лица погружаются в глубину чувств - они стыдливы, печальны или взволнованны, то от первого лица поют солисты группы банцян, например, в знаменитом отрывке из Сычуаньской оперы «Дашэнь» гаоцян дан именно в такой интерпретации. Напевы банцян имеют жанровую оформленность, приведем их наиболее распространенные виды: 
- «цинбан» - чистая подпевка-реплика, отклик на короткую фразу солиста;

- «хуньбан» - смешанная подпевка, ряд хоровых реплик;

- «ичан чжунбан» - «один поет, толпа подпевает» - в партии хора-комментатора выделен солист;

- «сюцзыбан» - подпевка короткими междометиями, в которой партии солиста и хора активно обмениваются репликами.

Основная роль подпевки заключается в том, чтобы максимально ярко описать происходящее на сцене и так же ярко выразить душевные переживания героев, намеренно сгустить краски и богатым музыкальным рядом усилить выразительное художественное воздействие.

Закулисные подпевания в высоких напевах Сычуаньской оперы в Китае ассоциируют с хоровым пением в древнегреческой трагедии. Этот своеобразный «бэк-вокал», древнекитайский и древнегреческий, различается лишь в методах или формах, совпадая по сути: и тот, и другой вид служат ярким выразителем чувств, транслятором психологического состояния героев, философским обобщением сложных глубокомысленных моментов драмы. Хор является активным двигателем драматургической динамики, сильнейшим средством эстетического и художественного воздействия. Из-за кулис он вступает в самые различные взаимоотношения с происходящим на сцене, которые можно охарактеризовать музыковедческими понятиями «согласие и гармония», «полифония», «контраст», «конфликт», «обобщение». Например, в известной в Китае и многократно представленной за рубежом пьесе Цзыянхэ «В поиске любви» партия банцян настолько изысканна, что все реплики хора вызывают непременный восторг у зрителей. В сцене размышлений изменника в его сумрачную песнь «Изгородь еще выше, в сумерках печаль, луна, словно вода, отражает башню» вторгаются закулисные реплики хора: «Сплошной холодный ветер». Красота песни «антигероя» провоцировала сочувственный отклик зрителей, их готовность внимать его рефлексии, однако суровый и возвышенный характер параллельной «комментирующей» линии мгновенно меняет модус зрительского восприятия. Сквозь призму высокой хоровой эпики обнажается истинный внутренний мир изменника, эгоизм и ничтожность его страданий, которые больше не вызывают сочувствия. Художественная полифоничность, драматургическая полифункциональность гаоцян - особое достояние Сычуаньской оперы, ее драматическая сила, форма воздействия которой сравнима с современными эффектами 3D.

Динамическое взаимодействие со столь активным хором требует от артиста высокого мастерства, не только вокального, но и актерского. У ведущего исполнителя голос должен быть чистым, чувственным и сильным. После реформ в Сычуаньской опере к исполнителю банцян также предъявили требование мастерства пения гаоцян, поэтому в большинстве случаев это были девушки с яркими высокими голосами, специально обученные и организованные в исполнительский коллектив, который существенно отличается от обычного хорового коллектива, даже если он участвует в театральной постановке. Своим мастерством хор должен довести слушателя до слез во время трагических моментов или заставить веселиться во время исполнения смешных сцен.

Логуцзинь. Сценическое действие в Сычуаньской опере, помимо вокально-хорового комментирования, поддерживается постоянной линией звукового сопровождения, осуществляемой ударными инструментами различного вида гонгами и барабанами. Ударные Сычуаньской оперы имеют собственное общее наименование - «Логуцзинь». Гонги и барабаны являются своеобразным элементом художественного стиля и исполнительского мастерства актеров. В искусстве высоких напевов в принципе изначально не использовались струнные инструменты - только ударные инструменты и вокально-хоровые подпевания. Это характерная черта гаоцян, если помнить о том, что большинство напевов в народном творчестве исполняются под аккомпанемент струнных - лютневых или скрипки эрху. Ударных инструментов в Сычуаньской опере насчитывается около 20 разновидностей, среди них выделяются следующие.

«Гушы» - барабанщик-дирижёр. Является лидером-дирижером оркестра китайского театра. Задача гушы - руководить оркестром, держать ритм, задавать атмосферу спектакля, создавать импульсивный фон для игры актеров.

«Сяошы» - маленький барабан. Звук у сяошы звонкий и высокий. Среди ударных инструментов он является ведущим инструментом, но подчиняется управлению гушы. При этом сяошы является инструментом для драматической сцены и отличается от ударных инструментов военного характера.

«Тишоу» - управляется гушы. Используется для регулировки такта напевов.

«Дало» - большой гонг. Изготавливается из меди, имеет название «храбрец» среди гонгов и барабанов в Сычуаньской опере. Демонстрирует силу, из-за разницы способов ударов с помощью большого гонга «дало» в зависимости от действия пьесы можно извлекать особые звуки с эффектом ветра, тучи, молнии, грома, дождя.

«Дабо» - большая чаша. Тембр простой и глубокий. Выразительность богато насыщенная, требующая виртуозного владения техникой игры. Исполнение на этом инструменте требует точности на высокой скорости.

«Эргу», также называют «тангу»: тембр звонкий и сильный. Во время исполнения используется для игры вместе с «дало», «дабо», образуя единое целое.

«Мало» - гонг. Имеет специфическую форму и игривый тембр. При исполнении лучших арий оперы используется во вступлении и играет впоследствии связующую роль.

«Цзяоцзы» - среди ударных инструментов для драматической сцены играет незаменимую роль при завершающих тактах.

Даже самая краткая характеристика каждого инструмента показывает общее назначение ударных: их тембры, яркие и выделяющиеся, а также разнообразная артикуляция осуществляют синтез музыкальной стороны оперы с драматическим и символическим рядом. Богатая палитра звуковых возможностей простирается 
от ритмического аккомпанемента до звукоподражательных «вторжений» в действие, отстраняющих происходящее или эмоционально заостряющих сюжетную ситуацию.

Тембры китайских ударных инструментов рельефны и выразительны, их звучания напоминают реплики и возгласы человека. Артисты могут, в зависимости от сюжетной линии, выбирать подходящий инструмент с нужным тембром для конкретной комбинации. Большое внимание уделяется способу удара в барабаны и гонги, требующего особого мастерства: китайские барабаны обладают особой чувствительностью к прикосновению, они способны выдавать множество оттенков ударного звука. Благодаря этому качеству ударные инструменты в Сычуаньской опере отлично играют роль рельефных аккомпанементов, сопровождающих пение. Напевы, исполняемые под аккомпанемент ударных, получили название «танси». Наиболее изящные танси великолепно сочетаются с прихотливой звуковой россыпью «гайбанцзы»- колотушки с дощечкой.

Напевы танси выделяются в отдельную группу благодаря их скрепленности с гайбанцзы. Изящный рисунок ритмов гайбанцзы, его виртуозная фактура оформляются в две хорошо узнаваемых ритмических модели. Подобно тому, как мажор и минор в гармонии мгновенно опознаваемы как обобщенные источники «радостного» и «грустного», ритмические модели гайбанцзы опознаются как источники «веселых» и «печальных» ритмов. Жизнерадостные или меланхоличные, задорные или унылые реплики и напевы украшаются кружевом ударных, усиливающих эмоциональное чувство и эстетически украшающих мелодии.

В регионах Наньчун, Мяньян и в других местах северного Сычуаня напев танси получил влияние циньских арий. А в музыке циньских арий преобладают печальные мотивы. Отсюда произошло формирование контрастных групп напевов, «печальная» часть которых привнесла в Сычуаньскую оперу колорит веселья с оттенками легкой грусти.

Помимо особой сложности исполнительства, искусство логуцзинь требует внимания к эстетике и стилю древней оперной традиции, которая сегодня по популярности проигрывает массовым жанрам - это общая для всего мира проблема. Поэтому в непростой ситуации нарушения преемственности передача навыков игры на ударных инструментах в Сычуаньской опере подвергается нелегкому испытанию. Линия ударных в Сычуаньской опере принадлежит к ее классическим элементам, и сохранение искусства игры на ударных инструментах сегодня осуществляется только в виде аудио- или видеозаписи оперных спектаклей.

Сычуаньская опера является уникальным видом сценического искусства, который имеет очаровательную и весьма утонченную музыкально-драматургическую систему. Этот вид традиционного театрального искусства Китая обладает собственной художественно-прикладной выразительностью, воплощенной в наборе колоритного реквизита и костюмов. Его актерская школа отличается высоким мастерством, а музыкальные краски имеют ярко выраженную самобытность.

Предпринятый анализ особенностей музыкального стиля Сычуаньской оперы позволяет сделать следующие выводы:

- художественная стилистика этого локального явления традиционной культуры самобытна и не повторяет черт Пекинской оперы;

- особенности музыкального стиля Сычуаньской оперы свидетельствуют о самостоятельности пути ее формирования и развития;

- дальнейшее изучение ее особенностей будет способствовать сохранению традиционной культуры Китая, интерес к которой в XXI столетии по-прежнему велик.

Список источников

1. Будаева Т. Б. Музыка китайского традиционного театра цзинцзюй (Пекинская опера): дисс. ... к. искусствоведения. М., 2011. 253 c.

2. Ван Дон Мэй. Великий шелковый путь в истории китайской музыкальной культуры: автореф. дисс. ... к. искусствоведения. СПб., 2004. 32 с.

3. Ван Цюн. Национально-культурные типы вокально-исполнительского искусства (на материале сравнения пекинской музыкальной драмы и европейской оперы) // Известия Российского государственного педагогического университета им. А. И. Герцена. 2008. № 51. С. 28-31.

4. Жуань Юнчэнь. Пекинская опера как синтетическое сценическое действо: автореф. дисс. ... к. искусствоведения. M., 2013. 29 c.

5. Ли Чао. Роль танца и пантомимы в музыкальной композиции пекинской оперы: автореф. дисс. ... к. искусствоведения. СПб., 2001. 24 с.

6. Лю Цзинь. Китайская национальная опера: 1920-1980 годы // Известия Российского государственного педагогического университета им. А. И. Герцена. 2009. № 117. С. 277-285.

7. Лю Чжань. Истоки и особенности китайской оперы // Человек, психология, экономика, право, управление: проблемы и перспективы: материалы XIV Междунар. науч. конф. Мн., 2011. С. 287-288.

8. Чэнь Ин. Китайская опера XX - начала XXI века: к проблеме освоения европейского опыта: автореф. дисс. ... к. искусствоведения. Ростов н/Д, 2015. 24 с.

9. 吴静. 论戏曲艺术对民族歌剧发展的作用 / 硕士学位论文. 北京. 中央音乐学院. 2011年. 231页 (У Цзин. О влиянии театрального искусства на развитие национальной оперы: дисс. на соискание степени магистра / Китайская консерватория. Пекин, 2011.231с.).

10. 崔保亚. 多学科综合的戏曲音乐研究方法 // 《湖北第二师范学院学报》. 武汉. 2009年. 第26卷第7期 (Цуй Баоя. Многостороннее изучение театральной музыки // Вестник Второго педагогического университета провинции Хубэй. 2009. № 26. Вып. 7). 


\title{
SPECIFICITY OF MUSICAL STYLISTICS OF THE SICHUAN OPERA
}

\author{
Xu Jian \\ Herzen State Pedagogical University of Russia, Saint Petersburg \\ 251104247@qq.com
}

The article examines a unique form of the traditional Chinese drama - opera of the Sichuan province, or the Sichuan opera. It differs cardinally from the world-famous Peking opera and other local forms of opera art. The Sichuan opera has its own aesthetics, technique and school of singing, but its basic heritage is a unique musical style, which combines original singing in high register (gaoqiang) to the accompaniment of percussion instruments (luogu jing) with vocal and choral recital (banqiang). The author analyses the features of the vocal stylistics of the Sichuan opera, describes percussion instruments in detail and presents types of choral commenting used in the opera.

Key words and phrases: traditional Chinese drama; regional specificity; Sichuan opera; high tunes gaoqiang; vocal and choral recital; accompaniment of percussion instruments (luogu jing).

УДК 78; 781

https://doi.org/10.30853/manuscript.2019.11.55

Дата поступления рукописи: 02.09.2019

В статье рассматривается музыкальный материал, используемый в рамках вузовского предмета «сольфеджио» в современном Китае. В китайской практике развития музыкального слуха усвоена установка на разнообразие ритмов, ладов и мелодий различных начиональных музыкальных языков, используемая в российском опьте воспитания музыканта. В предложенной работе автор дает краткий анализ учебных пособий Ли Чунгонга «Теория музыки», Сюй Цзина и Сунь Хуна «Сольфеджио», Ян Тонга «Учебник по гармоническому анализу», Лю Чжипина «Передовые методы обучения вокалу».

Ключевые слова и фразы: воспитание слуха; учебные пособия; Лю Чжипин; Ян Тонг; музыкальный материал; интонирование; традиционная культура; западные методики.

\section{Цзи Шаньшань}

Российский государственный педагогический университет имени А. И. Гериена, г. Санкт-Петербург 48632593@qq.com

\section{МУЗЫКАЛЬНЫЙ МАТЕРИАЛ В КИТАЙСКИХ УЧЕБНИКАХ СОЛЬФЕДЖИО}

Актуальность работы заключается в том, что в настоящее время в Китае усилился интерес к вопросам воспитания музыкального слуха, однако исследований, в полной мере освещающих эту проблему, не существует. Одним из важнейших компонентов воспитания музыкального слуха является музыкальный материал, используемый в учебниках сольфеджио. Вестернизация музыкальной культуры, под знаменем которой в сложной исторической обстановке происходило становление музыкального образования, прочно проникла и в воспитание и развитие музыканта. Именно музыкальный материал сольфеджио показателен и интересен как фактор, отражающий преломление западных музыкально-языковых элементов и совмещение их с национальными в среде обучения музыкантов.

Объект исследования данной статьи - музыкальный материал в учебниках сольфеджио; предмет - статус и специфика этой дисциплины в Китае. Цель работы - раскрыть некоторые проблемы воспитания музыкального слуха и дать характеристику используемого музыкального материала. Существующая литература по данной проблеме немногочисленна. Можно выделить «Методические статьи по сольфеджио» Ван Гуаняо [2], «Историю развития шанхайской школы Сюй Хуэ. 1850-2010» Ма Сюэйцяна [6], «Изучение полного учебного курса сольфеджио в Ухане» Хуан Цяня [8], «Классифицированный курс сольфеджио. Уровни 1-8» коллектива авторов [5], тезисы «Цели и задачи сольфеджио в Китае» Чжао Ишаня [9], которые в некоторой степени восполняют этот пробел. Однако «вопросы развития музыкального слуха в Китае требуют глубокого изучения» [3, с. 36]. Научная новизна заключена в том, что впервые рассмотрены некоторые учебные пособия и музыкальный материал, способствующий активному развитию слуха.

В конце XX - начале XXI века отмечается усиление интереса к этническим культурам, в том числе к этническим ритмам, к этнической мелодике, к этносольфеджио. В России, например, в музыкальные пособия подобного рода включены звукоряды и ритмические формулы традиционной восточной музыки Турции, Ирана, Греции, Индии, Кореи, Китая и других стран. Благодаря ритмам, ладам и мелодиям различных национальных музыкальных языков студенты могут воспринять и познакомиться с элементами многих новых музыкальных культур. В китайском опыте развития музыкального слуха происходит то же самое. Известно, что «становление системы музыкального образования в Китае вначале происходило под влиянием зарубежных методик музыкального образования и, в частности, российской музыкальной школы, но в то же время формировалась собственная уникальная система» [14, с. 309]. 